\title{
CORRESPONDENCES
}

\section{Alveolar ejection volume: a misnomer?}

\section{To the Editor:}

In their paper "Volumetric capnography in patients with acute lung injury: effects of positive end-expiratory pressure", BLANCH et al. [1] use a "new" term: "alveolar ejection volume" $(V \mathrm{AE})$. This is intended as an index of "... uneven ventilation/ perfusion of heterogeneous alveoli which may be useful to monitor in patients with ARDS [acute respiratory distress syndrome] receiving mechanical ventilation". Figure 1 in the article shows the plots of both expired expiratory carbon dioxide tension $\left(P \mathrm{E}, \mathrm{CO}_{2}\right)$ and the cumulative plot, instantaneous carbon dioxide production $\left(V \mathrm{CO}_{2}\right)$, against expired volume. The eye suggests that the airway or anatomical deadspace $(V \mathrm{D}, \mathrm{aw})[2]$ is about $180 \mathrm{~mL}$ in figure $1 \mathrm{a}$, and about $200 \mathrm{~mL}$ in figure $1 \mathrm{~b}$. The $V_{\mathrm{AE}}$ differs greatly between the two figures. In figure $1 \mathrm{~b}$ it places alveolar ejection about $200 \mathrm{~mL}$ later than $V$ D,aw.

$V_{\mathrm{AE}}$ was described, by the authors of the present paper, in this journal in 1997 [3]. The rationale given for it is that only gas from the last part of the expirate is pure alveolar gas, and therefore this part of the cumulative $V_{\mathrm{CO}_{2}}$ plot can be extrapolated to give a volume which better describes alveolar efficiency. In fact, the extrapolation merely reflects the fact that phase III slope [4] continues to change in some patients. The slope of the phase III is not caused by the final washout of airway deadspace gas as this occurs much earlier [5].

Diagrams of this sort, as pioneered by CUMMING and coworkers $[2,6]$, describe what portion of the expirate contributes to gas exchange, and what portion does not, i.e. forms a deadspace. There is no justification for using an arbitrarily decided computer algorithm to define a place in the middle of the alveolar tidal volume without any physiological basis. I believe that the cumulative $V^{2} \mathrm{CO}_{2}$ diagrams used in the paper by BLANCH et al. [1] are being incorrectly interpreted. As described by CuMming and coworkers $[2,6]$, they provide a useful alternative to, e.g. the method of FowLER [4] used to derive $V \mathrm{D}$,aw. The remaining part of the tidal volume, i.e. alveolar tidal volume, represents gas exchange at various ventilation/perfusion ratios including zero and infinity [1].

Bohr's deadspace fraction and phase III slope give a similar sort of information to $V_{\mathrm{AE}}$, a qualitative, but not quantitative, measure of the spread of ventilation/perfusion ratios. The mean slope of phase III, possibly normalized for degree of hyperventilation [4], is almost certainly more useful. From $\mathrm{CO}_{2}$ diagrams only important deductions can be made about the efficiency of $\mathrm{CO}_{2}$ clearance per unit ventilation, if arterial blood gas analysis is also performed [1]. In contrast, $V_{\mathrm{AE}}$ is merely a measure of the degree to which the slopes of both phase III and the cumulative plot, change with expired volume. Both within-units and between-units ventilation/perfusion abnormalities may be responsible for this [2]. By definition, in severe ventilation/perfusion abnormalities, where the "shoulder" of the $\mathrm{CO}_{2}$ diagram between phases II and III is poorly defined, $V_{\mathrm{AE}}$ will differ greatly from $V \mathrm{D}$,aw. However, $V_{\mathrm{AE}}$ is not a measure of any other commonly understood ventilatory parameter. It is a misnomer, and it is diffIcult to understand how it can be used to reliably reflect other known physiological abnormalities.

\section{R. Fletcher*, G.B. Drummond ${ }^{+}$}

*Directorate of Anaesthesia, Central Manchester Hospitals NHS Trust, Oxford Road, Manchester, M13 9WL, UK. Fax: 44 1614861096. ' Dept of Anaesthetics, Royal Infirmary, Edinburgh, EH3 9YW, Scotland, UK.

\section{References}

1. Blanch L1, Lucangelo U, Lopez-Aguilar J, Fernandez R, Romero PV. Volumetric capnography in patients with acute lung injury: effects of positive end-expiratory pressure. Eur Respir J 1999; 13: 1048-1054.

2. Fletcher R, Jonson B, Cumming G, Brew J. The concept of deadspace with special reference to the single breath test for $\mathrm{CO}_{2}$. Br J Anaesth 1981; 53: 77-88.

3. Romero PV, Lucangelo U, Lopez Aguilar J, Fernandez R, Blanch L. Physiologically based indices of volumetric capnography in patients receiving mechanical ventilation. Eur Respir J 1997; 10: 1309-1315.

4. Fowler WS. Lung function studies II: the respiratory deadspace. Am J Physiol 1948; 154: 405-410.

5. Horsfield K, Cumming G. Functional consequences of airway morphology. J Appl Physiol 1968; 24: 384-390.

6. Langley F, Even P, Duroux P, Nicolas RL, Cumming G. Ventilatory consequences of unilateral pulmonary artery occlusion. In: Distribution des echanges gareux pulmonaires. Paris, France, INSERM, 1976. WF D613 1975; pp. 209-212.

\section{From the authors:}

We read with great interest the comments of R. Fletcher and G.B. Drummond on the analysis of volumetric capnography recently reported by our group $[1,2]$. The discrepancy raised by R. Fletcher and G.B. Drummond and our findings relates to the concept of alveolar ejection volume $\left(V_{\mathrm{AE}}\right)$, and the difference between $V_{\mathrm{AE}}$ and anatomical or airways dead space $(V \mathrm{D}, \mathrm{aw})$. We think that $V_{\mathrm{AE}}$ is not a misnomer but we believe that there is a considerable misunderstanding of its pathophysiological interpretation.

According to the simplified hypothesis of sequential gas emptying, early expiration contains gas from apparatus and $V$ D,aw and afterwards from the alveoli, with a clear transition between both phases in a homogeneous lung. In disease, a serial stratification occurs as the lung becomes inhomogeneous. Consequently, the transition between airways and alveolar phases becomes undetermined or rather difficult to identify. According to this model, "pure" alveolar gas in this situation can only be collected at the end of expiration [1].

Even in a normal lung, complete homogeneity between lung units is unrealistic. Therefore, a level of tolerance should be allowed to account for the physiological inhomogeneity, as well as for the convection-diffusion interaction that occurred in the airways. This tolerance has been called in our previous studies "dead space allowance" (DSA), and modulates $V \mathrm{AE}$ determination on the volumetric (v) $\mathrm{CO}_{2}$ elimination $\left(V^{\prime} \mathrm{CO}_{2}(\mathrm{v})\right)$ curve [2].

Always in accordance with the model of sequential gas emptying, $V \mathrm{AE}$ represents the fraction of tidal volume that corresponds to alveolar volume with a level of heterogeneity lower than DSA. The level of DSA was based on a previous study where we assessed intra- and inter-individual variability 
and noise-to-signal ratio in healthy intubated subjects receiving mechanical ventilation. A DSA of 5\% had the best reproducibility and lower noise-to-signal ratio [3]. As expected, in healthy subjects (fig. 1a in our paper [4]) $V \mathrm{AE}$ corresponds narrowly to the difference between expired tidal volume and $V \mathrm{D}$,aw measured either by the methods of FOWLER [5] or by the method of LANGLEY [6] (personal observations). In disease (fig. $1 \mathrm{~b}$ in our paper [4]), alveolar heterogeneity is more prominent and $V_{\mathrm{AE}}$ (measured at 5\% DSA) is progressively lower, and parametrizes, as R. Fletcher and G.B. Drummond pointed out, the progressive bending of the raising limb of the $V^{\prime} \mathrm{CO}_{2}(\mathrm{v})$ curve. These phenomena are the consequence of the increased alveolar heterogeneity present during disease, no matter what its origin.

In fact, this model is used in the classical analysis of volumetric capnography (expiratory oxygen fraction; $\mathrm{FE}_{\mathrm{C}} \mathrm{CO}_{2}(\mathrm{v})$ ) [7], as R. Fletcher and G.B. Drummond stated in their letter. Analysis based on the shape of Phase III, Phase II or the transition from Phase II to Phase III, the clinical use of end tidal $\mathrm{CO}_{2}$, etc., are implicitly based in the model of serial compartments, and the simplified hypothesis of serial alveolar gas exhalation. In other studies, the so-called "alveolar sampling" is frequently based on the same model.

A second point is related to our purpose of obtaining reliable and easily computerized parameters in order to increase the understanding and clinical use of capnography to monitor respiratory function. We believe that one of the reasons of the relatively low application of capnography is that usual parameters (Phase III slope, $V \mathrm{D}$,aw) need to be measured

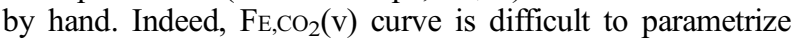
without a visual identification of reference points, even in healthy subjects. Moreover, the most sensitive part of the curve $\mathrm{FE}, \mathrm{CO}_{2}(\mathrm{v})$, the Phase III, has a considerable amount of noise. Finally, some of the most usual parameters of the $\mathrm{FE}_{\mathrm{C}} \mathrm{CO}_{2}(\mathrm{v})$ curve do not have a clear physiological basis, this is the case of the Phase III that assumes linearity for the rate of rise in the $\mathrm{FE}_{2} \mathrm{CO}_{2}(\mathrm{v})$ when usually the rate of raise is curvilinear. This implies that the identification of the beginning of the Phase III is subjective in the majority of patients, particularly in presence of significant heterogeneity (fig. $2 \mathrm{c}$ in our paper [4]). On the contrary, the $V^{2} \mathrm{CO}_{2}(\mathrm{v})$ curve is easier to parametrize because it only has two phases and one transition point. Moreover, the level of noise is very low, particularly in the part where the amount of information is crucial.

In our opinion, the $\mathrm{FE}_{2} \mathrm{CO}_{2}(\mathrm{v})$ curve is acceptable for visual understanding of the pathophysiology of some lung diseases, but $V^{\prime} \mathrm{CO}_{2}(\mathrm{v})$ allows automatic computerization of capnographic parameters, and seems more useful for continuous monitoring of alveolar heterogeneity.

P.V. Romero*, J. Lopez-Aguilar*, R. Fernández**, L. Blanch**

* Servei de Pneumologia and Unitat de Recerca Experimental, Hospital de Bellvitge, L'Hospitalet de Llobregat, Barcelona, Spain. **Servei de Medicina Intensiva, Hospital de Sabadell, Parc Tauli s/n, Sabadell, Spain.

\section{References}

1. Piiper J, Scheid P. Diffusion and convection in intrapulmonary gas mixing. In: Fishman AP, Farhi LE, Tenney SM, Geiger SR, eds. Handbook of Physiology. Vol. IV. Bethesda, MD, USA, American Physiological Society, 1987; pp. 51-69.

2. Romero PV, Lucangelo U, Lopez-Aguilar J, Fernandez R, Blanch L. Physiologically based indices of volumetric capnography in patients receiving mechanical ventilation. Eur Respir J 1997; 10: 1309-1315.
3. Romero PV, Lopez-Aguilar J, Lucangelo U, Blanch L. Alveolar ejection ratio elucidated from $V^{\prime} \mathrm{CO}_{2}$ versus $V \mathrm{~T}$ curves. Intensive Care Med 1995; 21: S45.

4. Blanch L, Lucangelo U, Lopez-Aguilar J, Fernandez R, Romero PV. Volumetric capnography in patients with acute lung injury: effects of positive end-expiratory pressure. Eur Respir J 1999; 13: 1048-1054.

5. Fowler WS. Lung function studies II: the respiratory deadspace. Am J Physiol 1948; 154: 405-410.

6. Langley F, Even P, Duroux P, Nicolas RL, Cumming G. Ventilatory consequences of unilateral pulmonary artery occlusion. In: Distribution des echanges gaseux pulmonaires. Paris, France, INSERM, 1976. WF D613. 1975; pp. 209-212.

7. Fletcher R, Jonson B, Cumming G, Brew J. The concept of deadspace with special reference to the single breath test for carbon dioxide. Br J Anaesth 1981; 53: 77-88.

\section{Difficult asthma}

The European Respiratory Society report on difficult asthma indicates the need for more co-ordinated research in this area [1]. This is highlighted by recommendations of the use in brittle asthmatics of continuous subcutaneous infusion of terbutaline (CSIT) in this and other recent state-of-the-art reviews [2].

There has, in fact, only been one published randomized placebo-controlled trial of such therapy [3]. Four patients with brittle asthma were randomized to CSIT or placebo. Two patients showed significant improvements in peak expiratory flow during the study period, whereas the other two showed no improvement. The only other study published in full was an open study, in which 13 of 17 patients with brittle asthma showed subjective and objective benefit [4]. A more recent study of CSIT in difficult asthmatics has demonstrated reduced healthcare requirements [5].

Thus, while there appears to be some benefit, CSIT is a technical procedure and may therefore have a large placebo effect, particularly in a group of patients with high psychosocial morbidity [6]. Treatment does have significant side-effects such as painful cutaneous nodules, tremor and palpitations.

I feel, therefore, that continuous subcutaneous infusion of terbutaline cannot be recommended for use except as part of a randomized controlled trial with clearly defined enrolment criteria.

\section{S. Packham}

Dept of Chest Diseases, Queen Elizabeth The Queen Mother Hospital, St. Peters Road, Margate, Kent, CT9 4AN. Fax: 01 843220048 .

\section{References}

1. Chung KF, Godard P, Adelroth E, et al. Difficult/therapyresistant asthma. Eur Respir J 1999; 13: 1198-1208.

2. Ayres JG, Miles JF, Barnes PJ. Brittle asthma. Thorax 1998; 53: 315-321

3. Ayres JG, Fish DR, Wheeler DC, et al. Subcutaneous terbutaline and control of brittle asthma or appreciable morning dipping. $B M J$ 1984; 288: 1715-1716.

4. O'Driscoll BR, Ruffles SP, Ayres JG, Cochrane GM. Long term treatment of severe asthma with subcutaneous terbutalineBr J Dis Chest 1988; 82: 360-367.

5. Packham SM, Haley AD, Petheram IS. The effects of subcutaneous infusion of terbutaline on the treatment of chronic severe asthma. Eur Respir J 1998; 12 (Suppl. 28): 38s.

6. Miles JF, Garden G, Tunnicliffe W, et al. Psychological morbidity and coping skills in patients with brittle and nonbriffle asthma: a case-control study. Clin Exp Allergy 1997; 27: 1151-1159. 